\title{
RHEOLOGICAL PROPERTIES OF STRAWBERRY PUREE JAM
}

\author{
NADA, Y.I***; M. F. ABD EL-SALAM*; \\ H. I. KHALIL** and M. A. EI NONO*
}

\begin{abstract}
The rheological properties of strawberry puree jam as a sample of some food gels investigated using Brookfield rotational viscometer at different temperatures $\left(30,40,50,60\right.$ and $70^{\circ} \mathrm{C}$ ) and different solid concentration of 40, 45, 50, 55 and $63 \%$. The investigated samples exhibited non-Newtonian pseudoplastic behaviour and fitted well to the power law model. The effect of concentration on the apparent viscosity was studied and fitted well to power law equation. The results observed that the apparent viscosity is exponentially proportional with the concentration of strawberry puree jam at all temperatures studied. The effect of temperature on the apparent viscosity of strawberry puree jam was fitted well to Arrhenius law; activation energy was $25.26-97.78 \mathrm{~kJ} / \mathrm{mol}$.
\end{abstract}

Keywords: Rheological properties; Viscosity; Food Gels; Activation energy; strawberry puree jam; Gels.

\section{1- INTRODUCTION}

heology is the science of the deformation and flow of matter or in
other words, the study of the manner in which materials respond
to applied stress and strain. The structure of matter can be physically characterized using this technique (Malkin et al, 2006).

Fruit hams are made by cooking fruit (pieces, pulp/or juice) with sugars, gelling agents (usually pectin) and edible acids (usually organic), and concentrating the mixture until a characteristic and suitable consistency is obtained (Diego et al, 2010). A gel is an intermediate between a solid and liquied processing both elastic (solid) and flow (liquid) characteristics. A number of foods are marketed in the form of gel that offers convenience to the consumers, as an example jam, jelly, confectionery products and desserts (Sutherland, 2007).

\footnotetext{
"Agric. Eng. Dept., Fac. of Agric., Ain Shams Univ.

**** Food. sci. Dept., Fac. of Agric., Ain Shams Univ.

*** Student of Post Graduate.
} 
Knowledge of rheological properties of fluid foods is also important for quality, understanding the texture, process engineering application, correlation with sensory evaluation, designing of transport system, equipment design (heat exchanger and evaporator), sizing pump capacity and power requirement for mixing etc. (Ibarz, 1996). The objective of this paper was to study the rheological properties of strawberry jam puree during processing and study the effect of temperature on the rheological property of jam puree.

\section{2- MATERIALS AND METHODS}

\subsection{Preparation of strawberry puree jam concentrations}

Five samples of strawberry jam puree with different concentrations (40, $45,50,55,63$ wt.b \%) were taken of the strawberry jam puree finish product.

Strawberry jam puree were obtained from fresh strawberry fruits which had been cleaned by a special washer then passed through a bucket elevator that transfer the strawberry fruit to the refiner which separate the pulp from fiber, and the pulp was transferred to the thermobreak which inhibit the activity of enzyme in the pulp, the pulp was then packed in a container, this process is applied to other types of fruits like fig, peach and etc.

The strawberry jam puree was manufactured using the following procedure:-

1. Transfer the strawberry puree to the vacuum pan with suction and, if needed, use a little treated water to rinse out the last of the material.

2. Addition of sugar to the pulp with ratio 1:1 strawberry pulp to sugar, and citric acid 2.6gm for one kilogram pulp.

3. Heat the vacuum pan to $80-90^{\circ} \mathrm{C}$ with stirring until the puree reach $63 \%$ concentration.

4. The strawberry jam puree is then pumped to the filler were it packed.

\subsection{Rheological properties of strawberry jam puree}

Knowledge of rheological properties of fluid foods is also important for quality, understanding the texture, process engineering application, correlation with sensory evaluation, designing of transport system, 
equipment design (heat exchanger and evaporator), sizing pump capacity and power requirement for mixing etc. (Ibarz, 1996).

Flow properties (shear rate, shear stress and apparent viscosity) of strawberry jam puree were measured directly using Brookfield digital rheometer Figure (1), model HA DVIII ultra (Brookfield Engineering laboratories INC). The puree was placed in a small sample adapter and SC4-21 spindle was selected for the sample measurement. A thermostatic water bath provided with the instrument was used to regulate the sample temperature Figure (2). The rheological parameters were studied at temperatures $\left(30,40,50,60,70^{\circ} \mathrm{C}\right)$, shear rates $\left(9.3-93 \mathrm{sec}^{-1}\right)$ and different concentrations $(40,45,50,55,63$ wt.b \%).

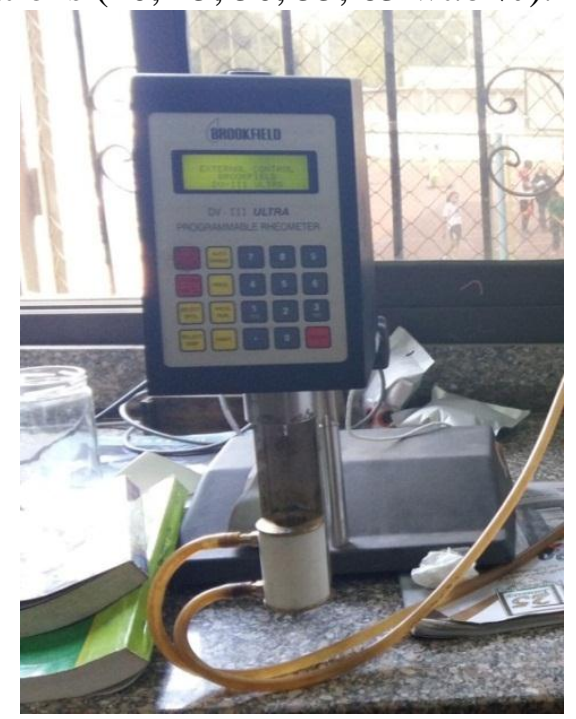

Figure (1): Photography picture of Brookfield Digital Viscometer model DV-III.

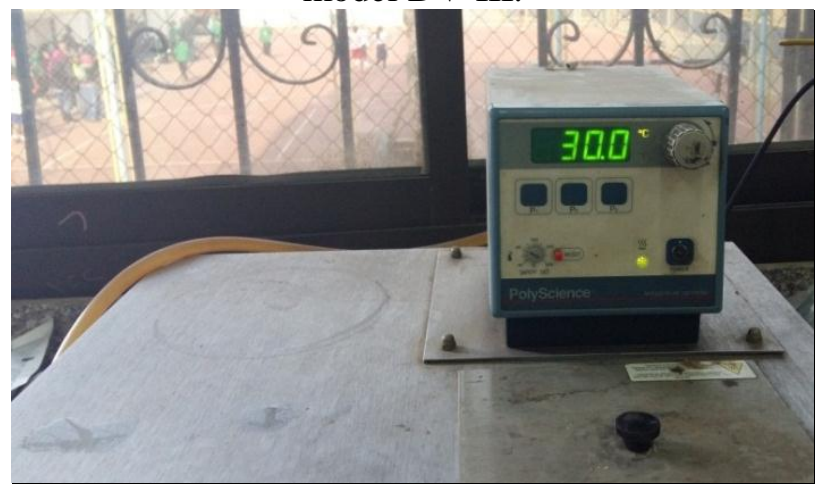

Figure (2): Photography picture of Thermostatic Water Bath. 
The rheological behaviour of The shear stress - shear rate data obtained fitted well to the constitutive equation of the pseudo plastic type:

$$
\tau=\boldsymbol{k} \boldsymbol{\gamma}^{\mathbf{n}}
$$

Where, $\tau$ is the shear stress, $\mathrm{Pa}$

$\mathrm{k}$ is the plastic viscosity (consistency index, pa. $s^{n}$ ).

$\gamma$ is the shear rate, $s^{-1}$

$\mathrm{n}$ is the behaviour index, where $\mathrm{n}$ is less than one for the pseudo plastic fluids .

The effect of shear rate on apparent viscosity reported by Sugai (2002),

$$
\boldsymbol{\mu}=\mathrm{k} \boldsymbol{\gamma}^{\boldsymbol{n - 1}}
$$

Where, $\mu$ is the apparent viscosity, pa.s

$\gamma$ is shear rate, $\mathrm{sec}^{-1}$

$\mathrm{k}$ is consistency index

The effect of temperature on the apparent viscosity was described by Arrhenius equation Speers et al, 1986 as follows:

$$
\mu=\mathrm{A} e^{E a / R T}
$$

Where, Ea is the activation energy, $\mathrm{J} / \mathrm{mol}$.

A is a constant,

$\mathrm{R}$ is the gas constant, $8.314 \mathrm{~J} / \mathrm{mol}$. $\mathrm{k}$,

$\mathrm{T}$ is the temperature, $\mathrm{K}$.

The change in viscosity with concentration could be described by an exponential (Vitali and Rao, 1984) or a power type of relationship (Rao et al, 1981) as follows:

$$
\boldsymbol{\mu}=\boldsymbol{a} \boldsymbol{C}^{\boldsymbol{b}}
$$

Where $\mathrm{a}$ and $\mathrm{b}$ are constants, $\mathrm{C}$ is the concentration.

\subsection{Measuring procedure of Brookfield viscometer is as follows:}

1. Ensure that the supplied cable is connected between a Brookfield Engineering labs DV- ПI Rheometer and COM1 or COM2 of our host computer. The rheometer is then turned on. The DV-III screen should display a message similar to the following:

2. To run RHEOCALC, type rheocalc at the Dos-prompt. After a few seconds, the screen turns white and then the following message is appeared:

Checking Rs-32 parts for Brookfield instruments 
After determining which Brookfield instruments are connected, the RHEOCALC main screen is appeared.

3. The arrow keys are used to move the high light bar in the main menu to the setup to the setup option then press the Return / Enter key to open the setup menu.

4. Choose the zero Rheometer in this menu. Message box is appeared asking us to insure that there is no spindle attached to the rheometer. After removing the spindle and acknowledging with a key press, the rheometer beings its auto zeroing process.

When the autozero is complete, a message box reminded you to attach the desired spindle, and press any key to continue.

5. To close the setup menu, press the Esc key and return to the main menu. Select the Gather option from the main menu.

6. Select the program option from the gather menu from the program menu, select Geometric.

7. From the Geometric program menu, select the new program option. At this point we are asked if we wish to run an up/down program. For no, press the "N" key to answer no.

8. The Geometric program entry window is opened to the left. This window required the entry of four program Entry of four program Parameters: a) Start RPM, b) End RPM, c) Time inter. Appropriate keys are used to enter the above parameters to cycle through the four entry fields, then use the tab key (again note the allowable keys on active key line).Allowable RPM values are 0.1 RPM with a minimum increment of 0.1 RPM. Time intervals are entered in minutes and second (MM:SS), and all four digits, must be entered (you need not enter the ":" as it automatically inserted for you).

9. When program entry is completed, press the Return / Enter key to accept the program. Select the begin program option from the Geometric program menu. The gather data windows are opened with the latter underneath the former. The spindle began to rotate the start 
RPM. The following pertinent gather information are appeared in the gather status window:
a. Current program step
b. total program steps
c. current spindle speed
d. time remaining to the next program step
e. Next program step speed and time interval.

The gather statues window toggles on and off (allowing you to see the gather data window underneath) by pressing the F3 key.

10. After each time interval has elapsed, a data point is taken and displayed in the gather data window before ramping to the next speed.

11. When the program is completed, press a key, to acknowledge this. The gather data windows are closed and the data get reviewed.

\subsection{Investigated parameters:}

The parameters that were investigated in this study are:

1. Shear rate as a function of shear stress.

2. Effect of shear rate on the apparent viscosity, $(9.3,18.6,27.9,37.2$, 46.5, 55.8, 65.1, 74.4, 83.7, 93 Sec-1).

3. Effect of temperature on apparent viscosity, $\left(30,40,50,60,70^{\circ} \mathrm{C}\right)$.

4. Effect of concentration (40, 45, 50, 55, 63 wt.b \%) of strawberry jam puree on apparent viscosity.

5. The activation energy at different shear rates $(9.3,18.6,27.9,37.2$, $46.5,55.8,65.1,74.4,83.7,93 \mathrm{Sec}-1)$ and temperatures $(30,40,50$, $\left.60,70^{\circ} \mathrm{C}\right)$.

\section{3- RESULTS AND DISCUSSION}

\subsection{Stress - Strain Rate Relations}

Figures (3 and 4) represent the flow-behavior of strawberry jam puree (40\% and 63\%) respectively measured at different temperatures. The results show that most samples exhibited non-Newtonian pseudo plastic behavior at the most studied temperatures and concentrations, the results observed that the shear stress was increased with the increase of shear rate Figures (3 and 4) at all temperatures and concentrations studied. The stress-strain rate data obtained fitted well to the constitutive equation (1) of the pseudo plastic type. 


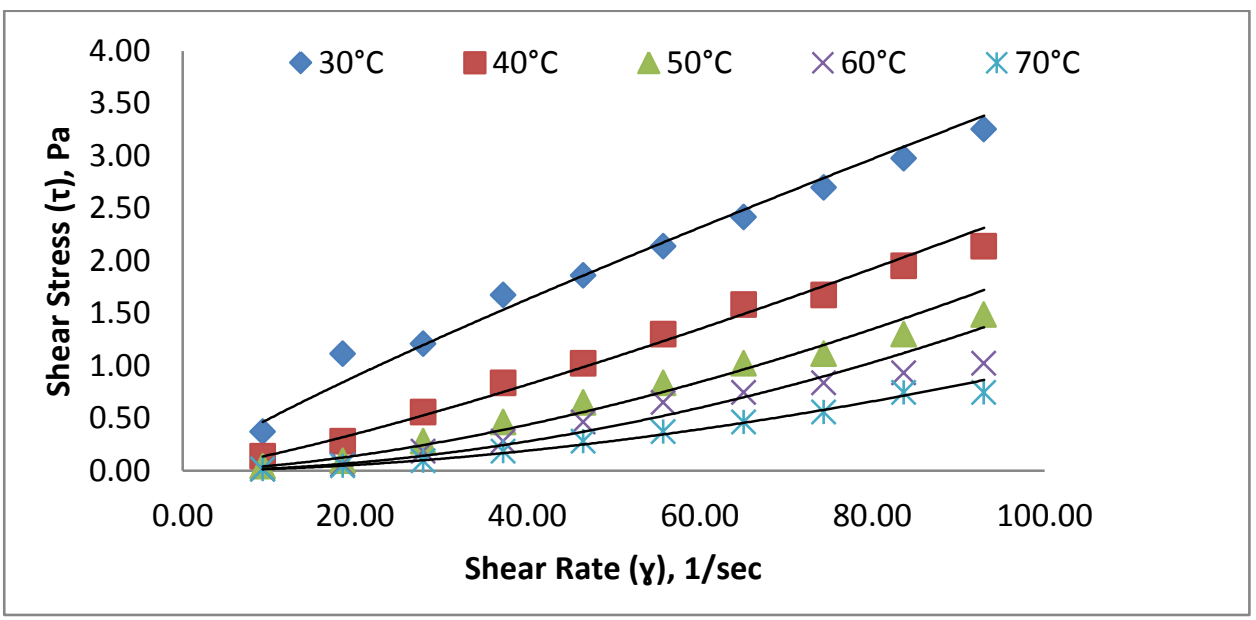

Figure (3): Relation between shear stress and shear rate at $40 \%$ solid concentration of strawberry puree jam at different temperatures.

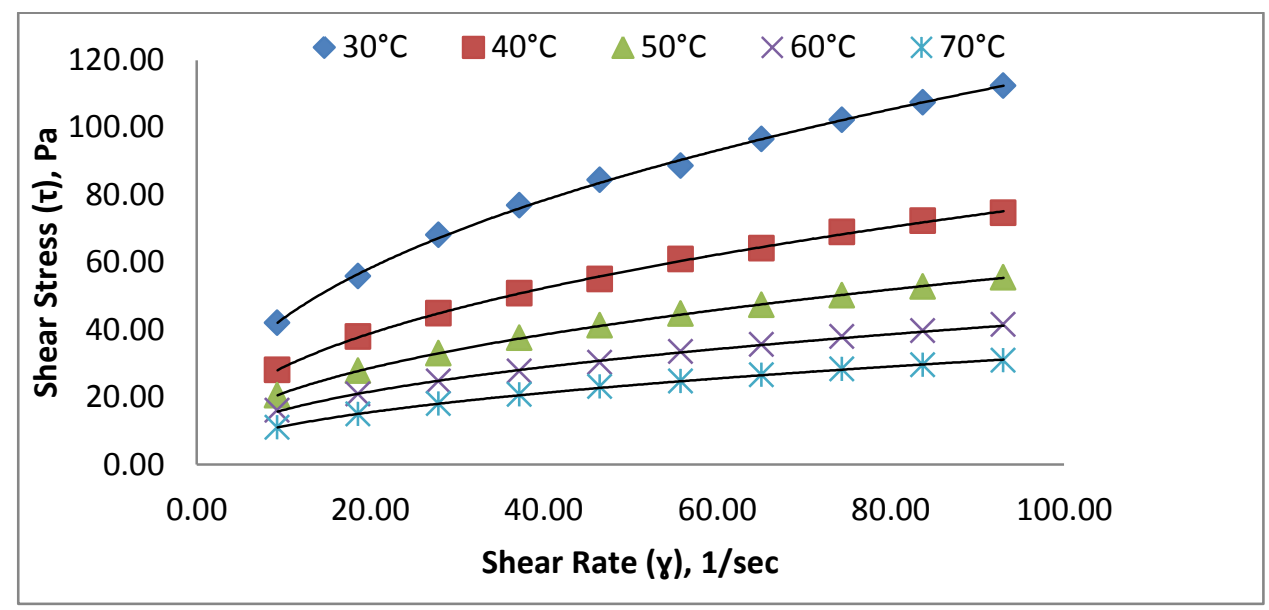

Figure (4): Relation between shear stress and shear rate at $63 \%$ solid concentration of strawberry puree jam at different temperatures.

The flow behaviour index (n) and consistency coefficient (K) were calculated from slope and intercept of straight line and were given in Table (1) for various concentration (40, 45, 50, 55, 63 wt.b \%) respectively. It is evident that the most values of flow behaviour index (n) is less than 1 for most cases which showed pseudoplastic nature of strawberry puree jam.

The results observed that all samples with different concentration behave the same trend. 
TABLE 1

Power law parameters $(\mathrm{k}, \mathrm{n})$ at different temperatures and concentrations:

\begin{tabular}{|c|c|c|c|c|c|c|c|c|c|c|}
\hline \multirow{3}{*}{$\begin{array}{c}\text { Temp. } \\
{ }^{\circ} \mathbf{C}\end{array}$} & \multicolumn{10}{|c|}{ Concentration } \\
\hline & \multicolumn{2}{|c|}{$40 \%$} & \multicolumn{2}{|c|}{$45 \%$} & \multicolumn{2}{|c|}{$50 \%$} & \multicolumn{2}{|c|}{$55 \%$} & \multicolumn{2}{|c|}{$63 \%$} \\
\hline & K & $n$ & K & $n$ & K & $n$ & K & $n$ & K & $\mathrm{n}$ \\
\hline $30 \mathrm{C}$ & 0.0679 & 0.8623 & 1.3006 & 0.4507 & 2.9647 & 0.4308 & 8.7474 & 0.3256 & 16.245 & 0.4268 \\
\hline $40 C$ & 0.0088 & 1.2297 & 0.2982 & 0.6885 & 0.9977 & 0.5976 & 3.0687 & 0.4853 & 10.778 & 0.4285 \\
\hline $50 C$ & 0.0011 & 1.6215 & 0.096 & 0.8455 & 0.7547 & 0.5691 & 1.8435 & 0.5279 & 7.9054 & 0.4296 \\
\hline $60 C$ & 0.0003 & 1.8784 & 0.0207 & 1.0766 & 0.5193 & 0.5607 & 1.1545 & 0.5595 & 6.1847 & 0.4184 \\
\hline $70 C$ & 0.0003 & 1.7865 & 0.0018 & 1.5578 & 0.2497 & 0.6083 & 0.9024 & 0.5332 & 4.0136 & 0.4522 \\
\hline
\end{tabular}

\subsection{Effect of shear rate on viscosity:}

Figures (5 and 6) show the relationship between the apparent viscosity of strawberry puree jam (50\% and 63\%) respectively, the results observed that the apparent viscosity decreases as shear rate increased, this can be attributed to the increase in intermolecular distances, because of the thermal expansion caused by the increase in temperature (Constenla et al, 1989).

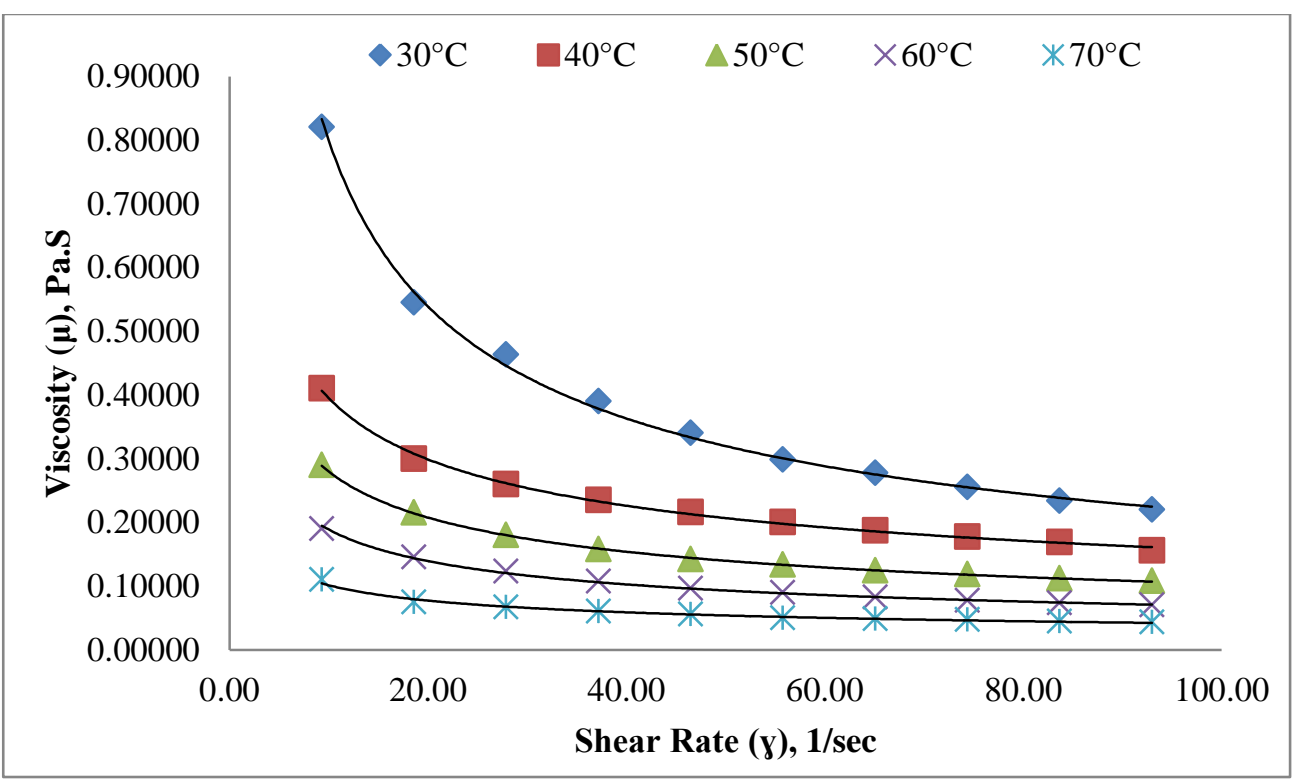

Figure (5): Relation between shear rate and viscosity of strawberry puree jam $(50 \%)$ at different temperatures. 


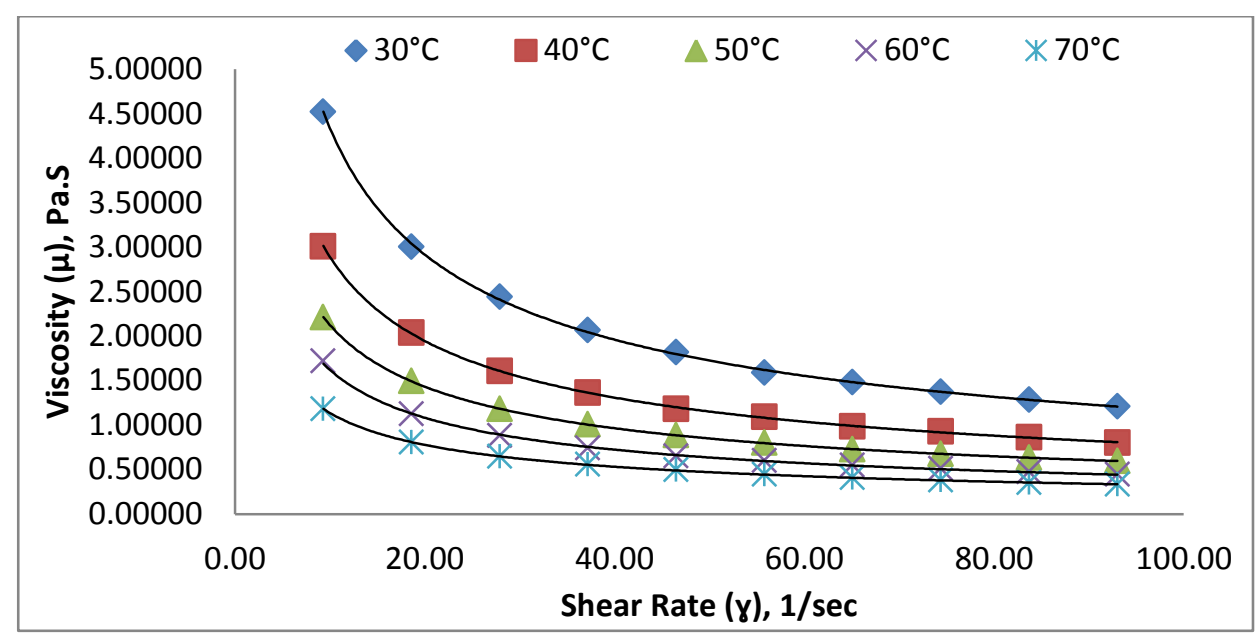

Figure (6): Relation between shear rate and viscosity of strawberry puree jam $(63 \%)$ at different temperatures.

\subsection{Effect of temperature on apparent viscosity of strawberry puree jam:}

Figures $(7,8,9,10$ and 11) show the effect of temperature on apparent viscosity $(40 \%, 45 \%, 50 \%, 55 \%$ and $63 \%)$. The results showed that the apparent viscosity decreases as temperature increased of all samples studied.

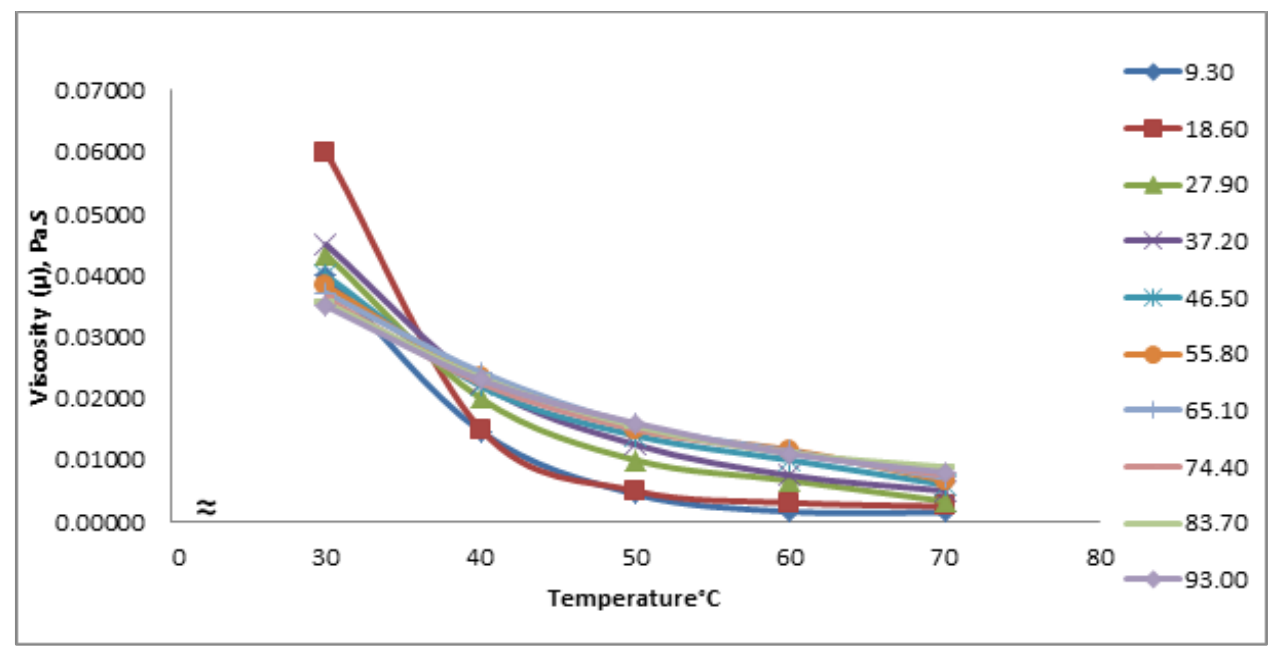

Figure (7): Effect of temperature on apparent viscosity of strawberry puree jam (40\%) at different shear rates.

Figure (7), A fluctuation in viscosity decrease over a certain range of concentration was appeared; this may be explained due to agglomeration 
of dispersed solid particles around the spindle which leads to a fictitious increase in viscosity. However, at higher concentration, the fluctuations in viscosity decrease where the curves tend to be parallel to each other Figures (8, 9, 10 and 11).

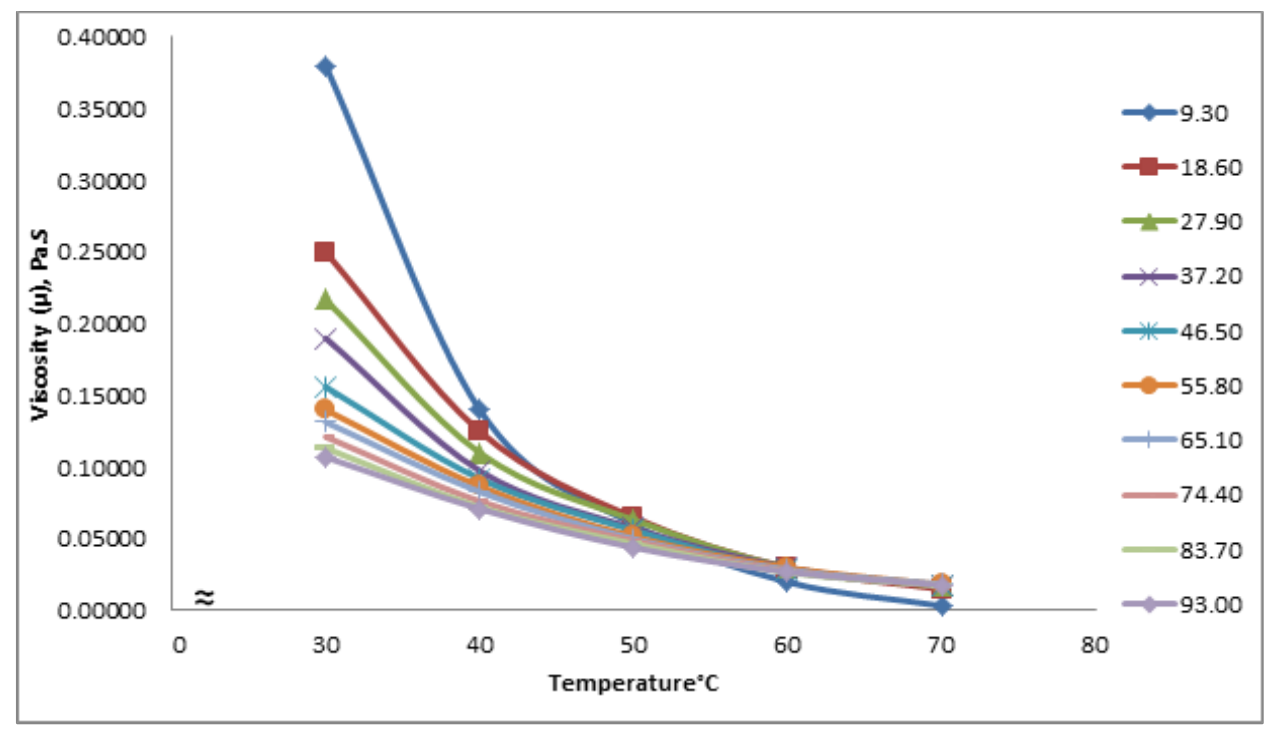

Figure (8): Effect of temperature on apparent viscosity of strawberry puree jam (45\%) at different shear rates.

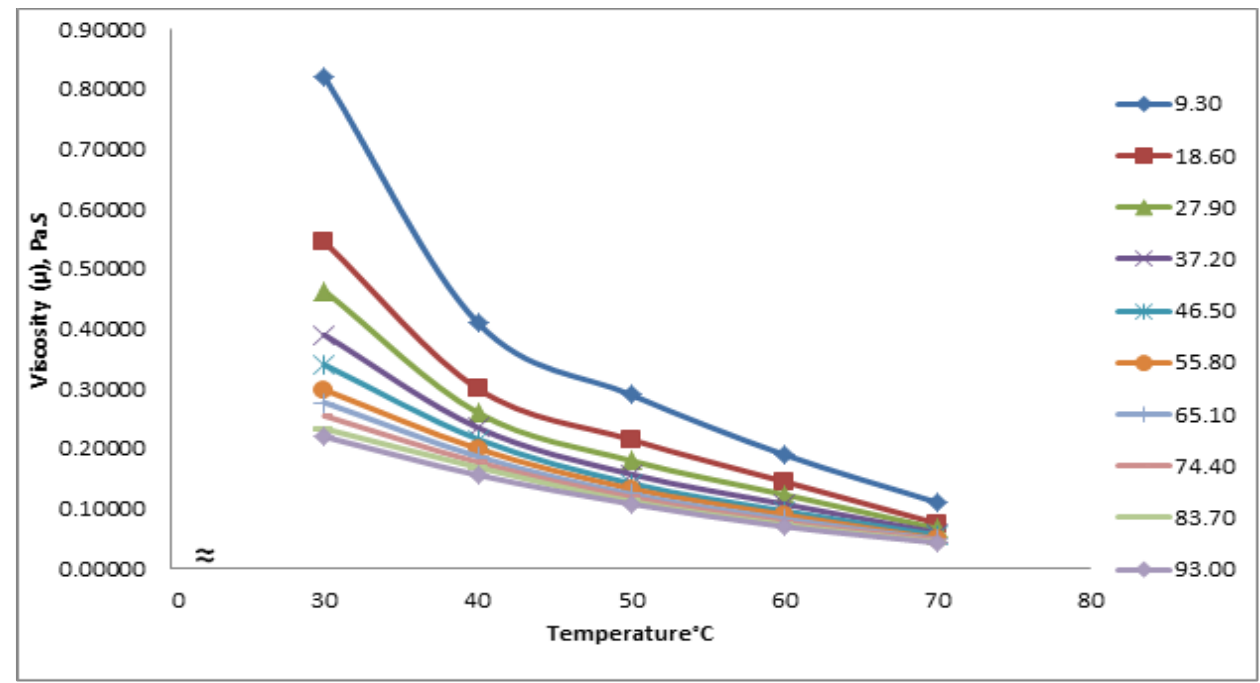

Figure (9): Effect of temperature on apparent viscosity of strawberry puree jam (50\%) at different shear rates. 


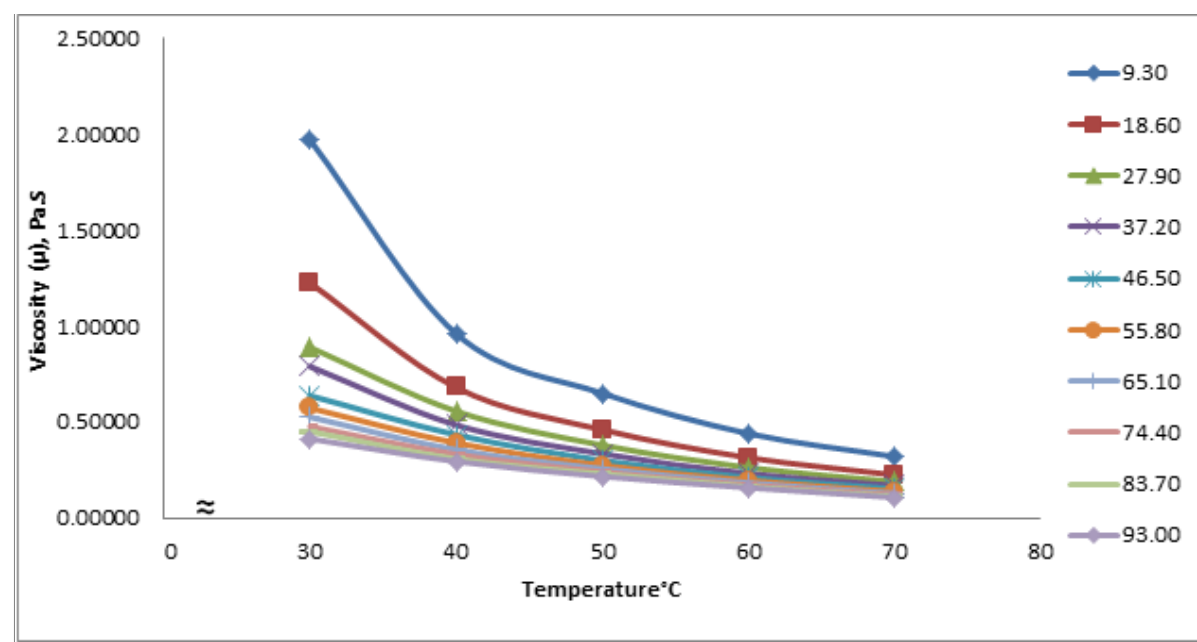

Figure (10): Effect of temperature on apparent viscosity of strawberry puree jam $(55 \%)$ at different shear rates.

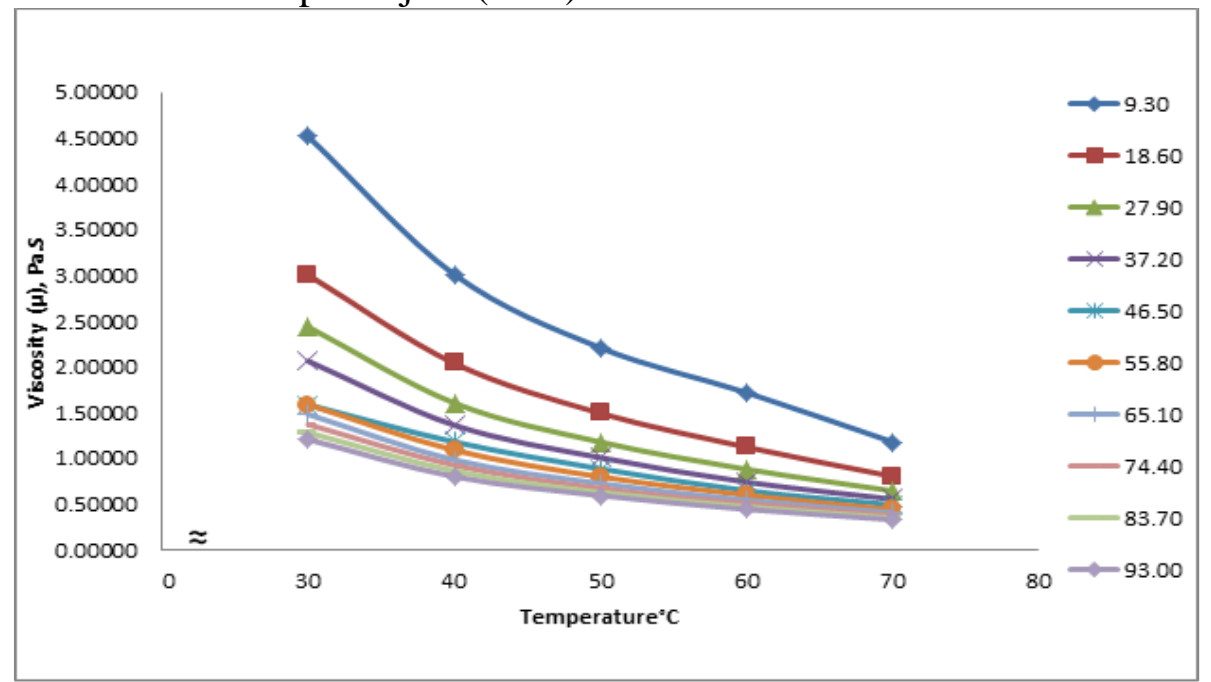

Figure (11): Effect of temperature on apparent viscosity of strawberry puree jam $(63 \%)$ at different shear rates.

The activation energy of strawberry puree jam at different shear rates (9.3 - $93 \mathrm{sec}^{-1}$ ) was determined. The results were fitted well to Arrhenius model (Eq. 3) Speers et al, 1986.

An activation energy is necessary for moving of a molecule, and as the temperature increases, the liquid flows more easily due to higher activation energy at high temperatures (Gurses and Bayrakceken, 1996). Table (2) shows that activation energy increased with increasing temperature at all shear rates studied, the same was observed for low 
concentrations According to Steffe (1996), in a system, higher Ea values indicate a more rapid change in viscosity with temperature. These results applicability of the Arrhenius model to the apparent viscosity versus temperature data of the present work agree with these obtained for tamarind juice concentrates (Ahmed et al, 2007).

The parameters obtained from Arrhenius model by curve fitting are given in Table (2).

\section{TABLE 2}

Activation energy (Ea) for strawberry jam puree at different shear rates

\begin{tabular}{|c|c|c|c|c|c|}
\hline \multirow{2}{*}{ shear rate $\mathrm{S}^{-1}$} & \multicolumn{5}{|c|}{ Activation Energy J/ mol } \\
\cline { 2 - 6 } & $\mathbf{4 0 \%}$ & $\mathbf{4 5 \%}$ & $\mathbf{5 0 \%}$ & $\mathbf{5 5 \%}$ & $\mathbf{6 3 \%}$ \\
\hline 9.3 & 76263 & 97789 & 41392 & 38337 & 28056 \\
\hline 18.6 & 69473 & 60872 & 40481 & 36046 & 27920 \\
\hline 27.9 & 53900 & 55505 & 39899 & 33209 & 28159 \\
\hline 37.2 & 47602 & 51394 & 39042 & 32971 & 27936 \\
\hline 46.5 & 39648 & 47552 & 38110 & 30771 & 25267 \\
\hline 55.8 & 36211 & 44249 & 37643 & 30521 & 27248 \\
\hline 65.1 & 34986 & 42984 & 37033 & 30011 & 27409 \\
\hline 74.4 & 33263 & 42202 & 36100 & 29273 & 27416 \\
\hline 83.7 & 30468 & 40579 & 35737 & 29290 & 27584 \\
\hline 93 & 31906 & 39126 & 35014 & 28683 & 27453 \\
\hline
\end{tabular}

In this study, the magnitudes of activation energy of the samples for the entire temperature range were determined by linear regression analysis. From Table (2), the magnitude of activation energy increase with the temperature. Besides, (Rha, 1975) noted that the decrease in viscosity with increasing shear rate is related to the increasing alignment of constituent molecules.

\subsection{Effect of concentration on viscosity:}

The effect of concentration on the apparent viscosity of strawberry jam puree at shear rate values $9.3-93 s^{-1}$ was investigated over a temperature range $30-70^{\circ} \mathrm{C}$. Figures $(12,13,14,15$ and 16) show the relation between the apparent viscosity against the concentration at shear rate $93 \mathrm{~S}^{-1}$. 


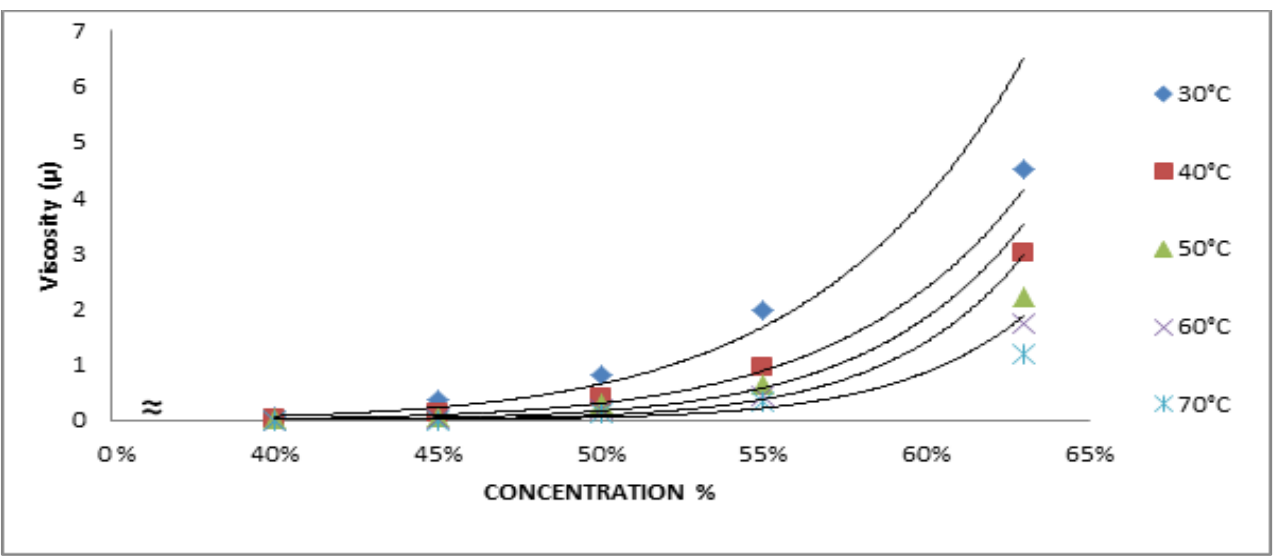

Figure (12): Effect of concentration on viscosity at different temperatures, at shear rate $=9.3 \mathrm{sec}^{-1}$.

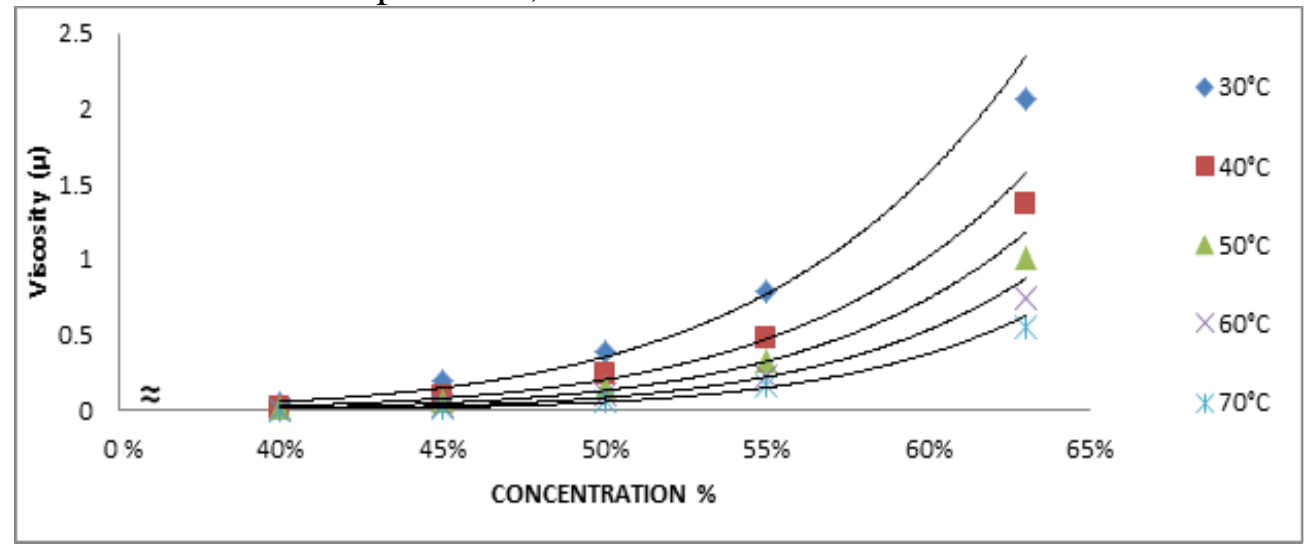

Figure (13): Effect of concentration on viscosity at different temperatures, at shear rate $=37.2 \mathrm{sec}^{-1}$.

These data have been fitted using Eq. (4)

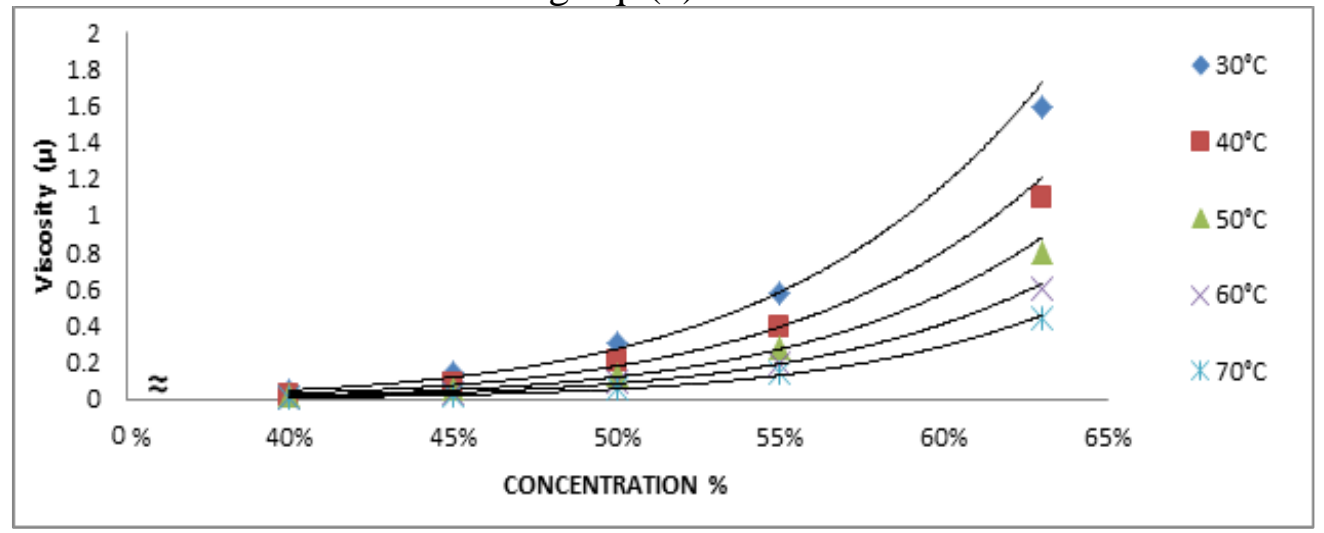

Figure (14): Effect of concentration on viscosity at different temperatures, at shear rate $=55.8 \mathrm{sec}^{-1}$. 


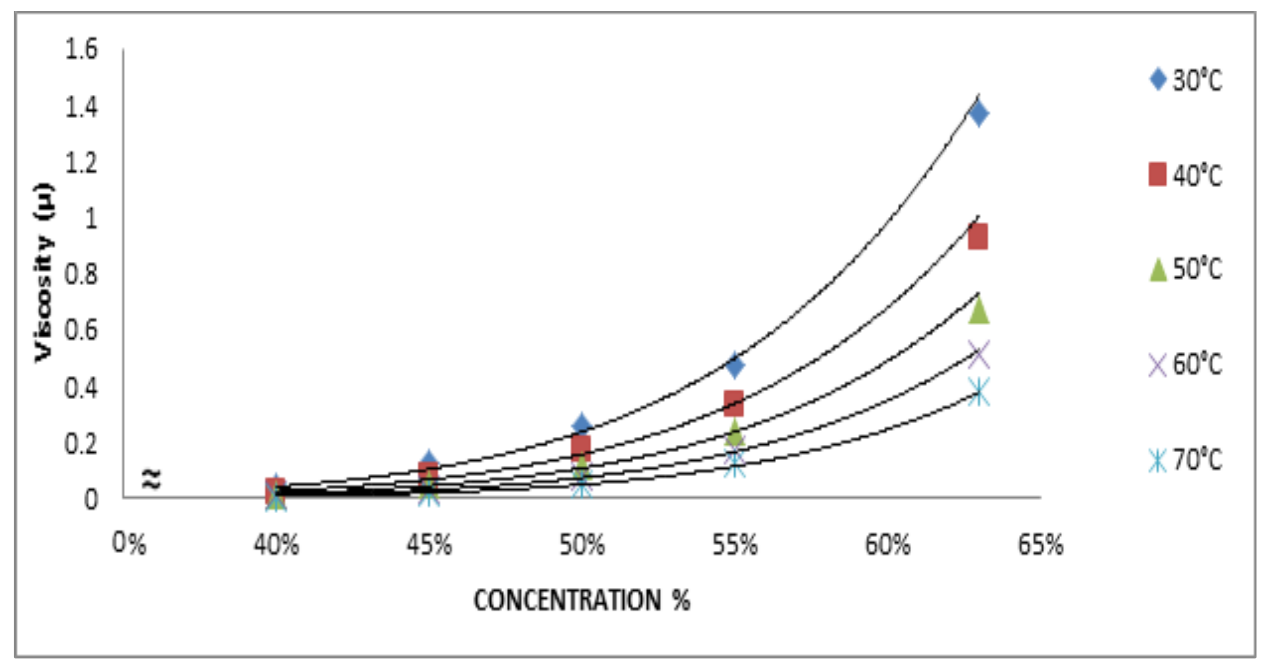

Figure (15): Effect of concentration on viscosity at different temperatures, at shear rate $=74.4 \mathrm{sec}^{-1}$.

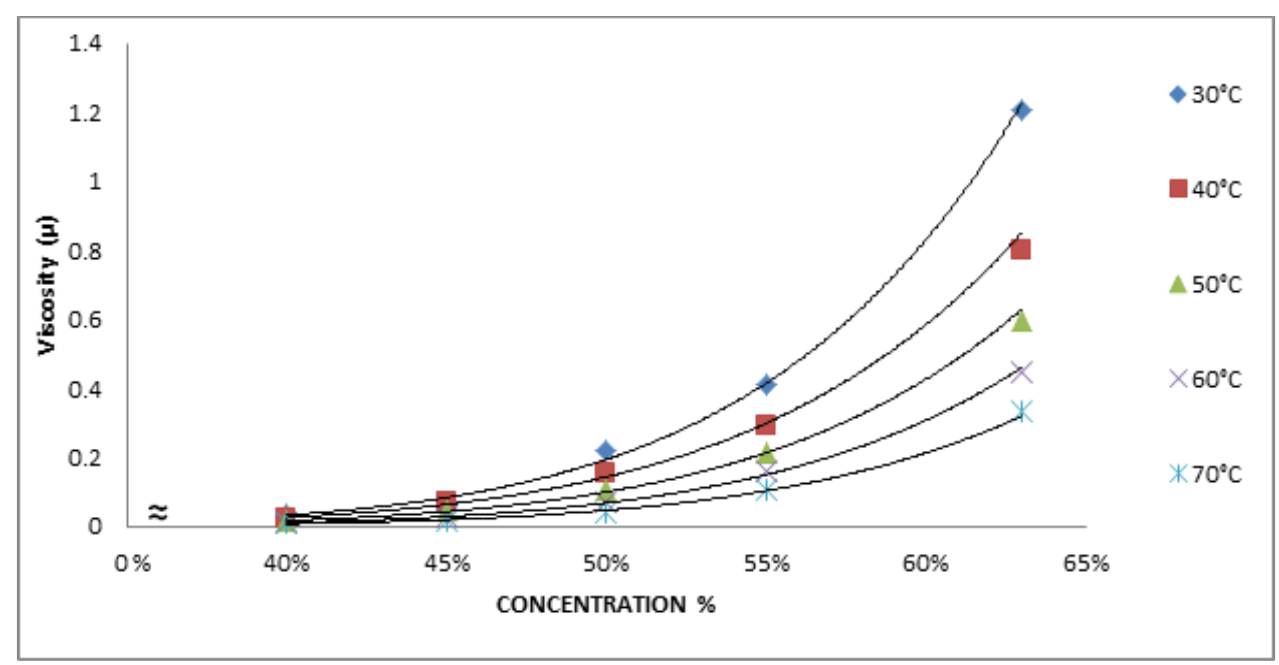

Figure (16): Effect of concentration on viscosity at different temperatures, at shear rate $=93 \mathrm{sec}^{-1}$.

The parameters of equation (4) were tabulated in Table (4) at different temperatures. At all temperatures, the apparent viscosity of strawberry jam puree increased with increasing concentrations. Figures (12, 13, 14, 15 and 16), this agreed with the findings the results observed that jam puree at higher concentration will have higher viscosity. This is probably due to the presence of more low and high molecular weight solutes such as salts, acids, pectin and other particles in strawberry jam puree in the 
higher concentration. The same trend was observed at all shear rates studied.

\section{Table (4)}

Parameters ( $\mathrm{a}$ and $\mathrm{b}$ values) of $\mathrm{Eq}(4)$ at different temperatures at shear rate $93 \mathrm{sec}^{-1}$.

\begin{tabular}{|c|c|c|c|c|c|c|c|c|c|c|}
\hline \multirow{3}{*}{ 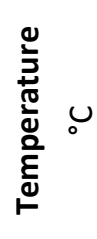 } & \multicolumn{10}{|c|}{$\begin{array}{c}\text { shear rate } \\
\mathrm{S}^{-1}\end{array}$} \\
\hline & \multicolumn{2}{|c|}{9.3} & \multicolumn{2}{|c|}{18.6} & \multicolumn{2}{|c|}{27.9} & \multicolumn{2}{|c|}{37.2} & \multicolumn{2}{|c|}{46.5} \\
\hline & a & b & $\mathbf{a}$ & b & a & b & a & b & a & b \\
\hline 30 & 657.5 & 9.9892 & 177.49 & 8.4774 & 147.78 & 8.5473 & 102.91 & 8.1847 & 86.16 & 8.1577 \\
\hline 40 & 774.75 & 11.328 & 320.76 & 10.384 & 145.87 & 9.3695 & 93.593 & 8.8464 & 71.526 & 8.5797 \\
\hline 50 & 1652.8 & 13.308 & 577.53 & 12.036 & 192.24 & 10.216 & 95.284 & 9.5029 & 63.578 & 8.9933 \\
\hline 60 & 3519.3 & 15.317 & 594.75 & 12.747 & 155 & 10.752 & 93.602 & 10.116 & 53.12 & 9.3341 \\
\hline 70 & 3021.2 & 15.985 & 401.5 & 12.824 & 175.58 & 11.662 & 81.158 & 10.524 & 50.969 & 9.8748 \\
\hline
\end{tabular}

\begin{tabular}{|c|c|c|c|c|c|c|c|c|c|c|}
\hline \multirow{3}{*}{ 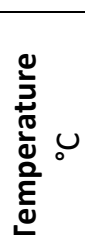 } & \multicolumn{10}{|c|}{$\begin{array}{c}\text { shear rate } \\
\mathrm{S}^{-1}\end{array}$} \\
\hline & \multicolumn{2}{|c|}{55.8} & \multicolumn{2}{|c|}{65.1} & \multicolumn{2}{|c|}{74.4} & \multicolumn{2}{|c|}{83.7} & \multicolumn{2}{|c|}{93} \\
\hline & a & b & a & b & a & b & a & b & a & b \\
\hline 30 & 69.18 & 7.9918 & 61.09 & 7.9059 & 52.805 & 7.7999 & 56.13 & 8.1044 & 48.578 & 7.9653 \\
\hline 40 & 55.743 & 8.2952 & 42.88 & 7.9948 & 41.233 & 8.0366 & 21.856 & 7.3568 & 29.757 & 7.6938 \\
\hline 50 & 48.451 & 8.6776 & 37.87 & 8.3861 & 33.951 & 8.3024 & 28.676 & 8.1105 & 24.847 & 7.957 \\
\hline 60 & 36.41 & 8.7885 & 30.95 & 8.6434 & 27.149 & 8.5266 & 23.631 & 8.3923 & 20.907 & 8.2571 \\
\hline 70 & 34.556 & 9.3747 & 26.642 & 9.0291 & 22.147 & 8.81 & 15.419 & 8.2949 & 14.935 & 8.3188 \\
\hline
\end{tabular}

\section{4- CONCLUSSION}

Rheology is the science of the deformation and flow of matter or in other words, the study of the manner in which materials respond to applied stress and strain. In this study strawberry puree jam as a sample of food gels behaved as a non-Newtonian pseudoplastic fluid at all the studied temperatures and concentrations, in which the stress is a non- linear 
function of shear rate. The apparent viscosity decreases with increasing temperature up to $\mathrm{v}_{0}{ }^{\circ} \mathrm{C}$. The results showed that a fluctuation in viscosity decrease as concentration increased. The results observed that the relation between temperature and viscosity was fitted to Arrhenius model with an activation energy ranged between $25.26-97.78 \mathrm{~kJ} / \mathrm{mol}$ Also, Viscosity increases with the increase of concentration for all temperatures studied at constant shear rate. The effect of concentration on the apparent viscosity of strawberry puree jam followed the power law model. While studying the behavior of strawberry puree jam as a sample of food gels

\section{5- REFERENCES}

Ahmed, J., Ramaswamy, H.S. and Sashidhar, K.C. 2007. Rheological characteristics of tamarind ( Tamarindus indica L.) juice concentrates. LWT - Food Science and Technology 40: 225-231

Constenla, D. T., Lozano, J. E., \& Crapiste, G. H. (1989). Thermophysicalproperties of clarified apple juice as a function of concentration and temperature. Journal of Food Science, 54(3), 663-668.

Diego, B. G., Alqain, Y. E., \& Harjinder, S. (2009). "High Methoxyl pectin / apple particles composite gels: Effect of particle size and particle concentration on mechanical Properties and gel structure", J of texture studies, 41, PP 171-189.

Gurses, A., \& Bayrakc eken, S. (1996). Deneysel Fizikokimya. Ataturk Universitesi Yayn no: 807. K.K. Egitim Fak. Yayin no: 62. Ders Kitaplari Serisi no: 48. Erzurum, Turkiye. In Memnune S., M.

Ibarz, A. (1996). " Rheological behavior of sloe (Prunus Spinosa) fruit juices. Journal of food engineering 27: 423-430. Pear juice Concentrates", J. of Food Eng., Vol.6, Pp. 57-63.

Rao, M. A., Bourne, M. C., \& Cooley, H. J. (1981). Flow properties of tomato concentrates. Journal of Texture Studies, 12, 521-538. 
Rha, C. (1975). Theories and principles of viscosity. In C. Rha (Ed.), Theory: Determination and control of physical properties of food Materials (pp. 7-249).Dordrecht, The Netherlands: Reidel.

Malkin, A. I. A., Malkin, A. Y., \& Isayev, A. I. (2006). Rheology: concepts, methods \& applications: Chem Tec Pub.

Speers R.A. and Tung, 1986. " Concentration and Temperature Dependence of Flow behaviour of Xanthan Gum dispersions", J. of Food Sci., Vol. 51, No.1, Pp 96-98,

Steffe, J. F. (1996). Rheological methods in food process Engineering (2nd Ed.). East Lansing, ). Michigan, USA: Freeman Press.

Sugai, A.Y. (2002).Processamento descontınuo de pure de manga (Magifera indica Linn), Variedade Haden: Estudo da viabilidade do produto para pronto consumo(pp. 82). M.S. thesis. Sao Paulo,Brasil: Universidade de S̃o Paulo.

Sutherland, I.W. (2007). Biotechnology of microbialpoly saccharides in food, In: food biotechnology. $2^{\text {nd }}$ Ed., pp. 193-220. Shetty, K., Paliyath, G., Pometto, A. and Levin, E., Eds. CRC press, Boka Raton, FL.

Vitali M.A and Rao A.A.( 1984). Flow Properties of Low-Pulp Concentrated Orange Juice: Effect of Temperature and Concentration, J. of Food Sci., Vol. 49, Pp. 882-888.

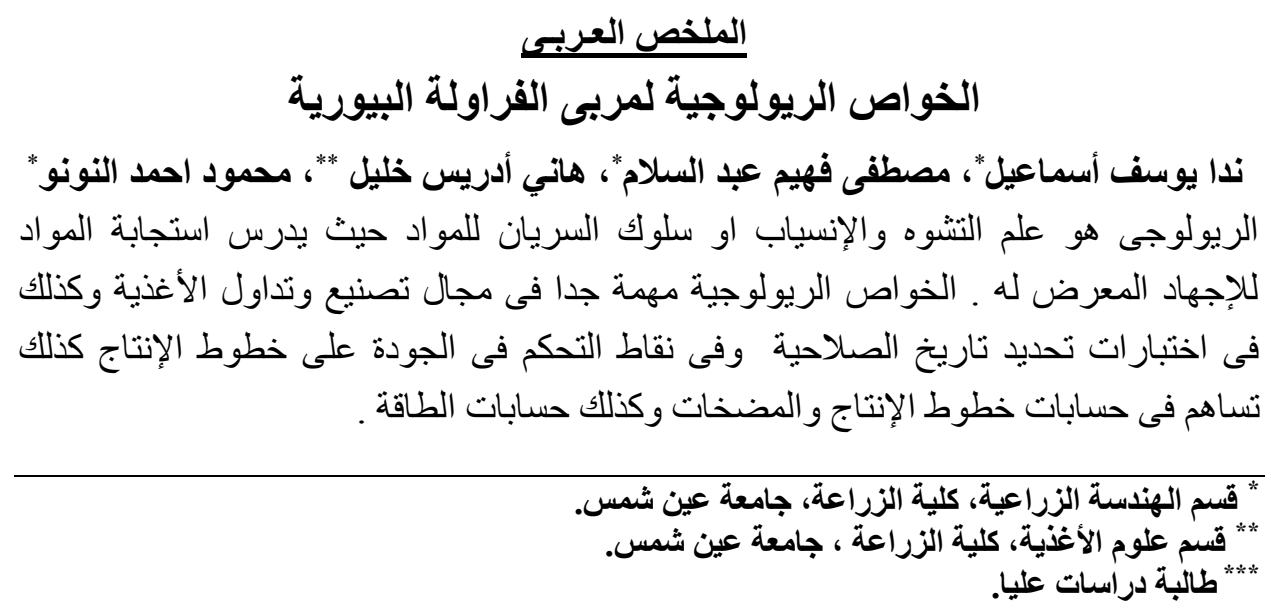


فى هذا البحث تم دراسة الخواص الريولوجية لمربي الفراولة البيوريه كمثال للاطعمة الجلية

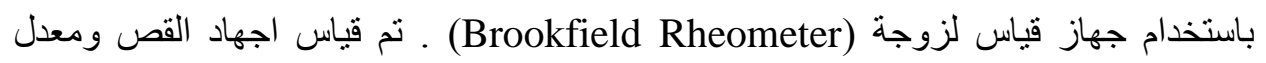

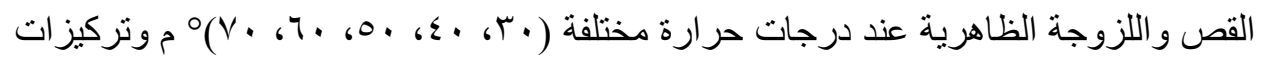

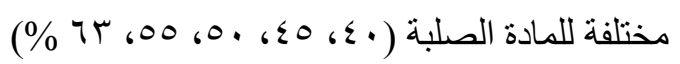

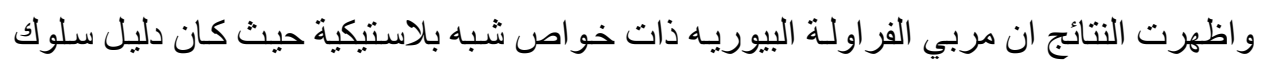

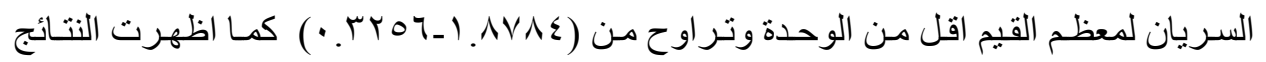

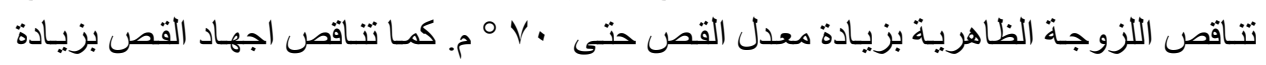

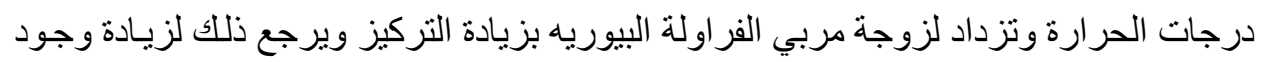

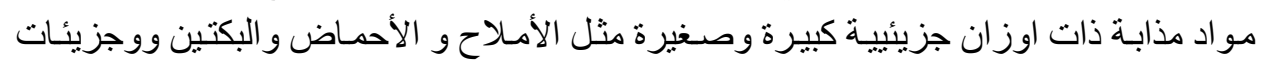

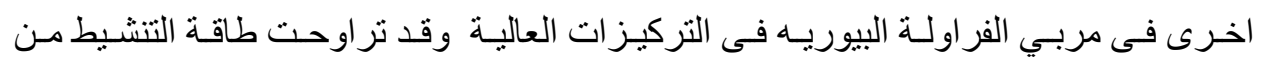

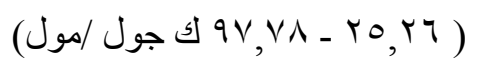

